\title{
AVALIAÇÃO E ACOMPANHAMENTO AUDIOLÓGICO APÓS MENINGITE BACTERIANA
}

\author{
MARIA INESS VIEIRA COUTO*, SILVIA ROBERTA GESTEIRA MONTEIRO**, \\ IDA LICHTIG***, ERASMO BARBANTE CASELLA****, \\ RENATA MOTA MAMMEDE CARVALLO ${ }^{* * * * *}$, JESSIE MEDEIROS DE NAVARRO******
}

\begin{abstract}
RESUMO - A deficiência auditiva é uma das sequelas da meningite bacteriana que ocorre com maior frequência em crianças. Este estudo descreve o perfil audiológico (periférico e central) de crianças internadas com diagnóstico de meningite bacteriana. Nas 89 crianças que compareceram ao seguimento audiológico após a alta hospitalar e foram submetidas aos testes audiológicos, os resultados evidenciaram que $85,4 \%$ apresentaram acuidade auditiva normal em ambas orelhas, $10,1 \%$ apresentaram deficiência auditiva neurossensorial bilateral e 4,5\% apresentaram deficiência auditiva neurossensorial unilateral. Nos testes que avaliaram as habilidades de processamento auditivo, os resultados mostraram que $10 \%$ dessas crianças apresentaram alteração no desempenho de localização auditiva e de reconhecimento de sentenças com mensagem competitiva ipsilateral.
\end{abstract}

PALAVRAS-CHAVE: deficiência auditiva, meningite, processamento auditivo.

\section{Audiological assessment and follow-up post bacterial meningitis}

ABSTRACT - Hearing loss is the more frequent sequel of bacterial meningitis in children. This study describes the audiological profile (peripheric and central) of 89 children admitted to the hospital wards with the diagnosis of bacterial meningitis. Those children attended audiological follow up, after their hospital descharge, and were submitted to audiological tests. The results showed that $85.4 \%$ among them presented normal hearing in both ears $10.1 \%$ presented bilateral neurosensorial hearing loss and $4.5 \%$ presented unilateral neurosensorial hearing loss. The results from the auditory processing skills assessment showed that $10 \%$ of those children presented auditory localization and recognition of sentences with competitive messages (Paediatric Sentences Identification - ipsilateral) disorders.

KEY WORDS: hearing loss, meningitis, auditory processing.

Apesar de todo avanço científico, a meningite bacteriana ainda é problema mundial, afetando principalmente crianças. Daquelas que sobrevivem à doença, cerca de 2,4 a $29 \%$ apresentam como sequela, dentre outras, a deficiência auditiva, que consequentemente afetará o desenvolvimento global das crianças ${ }^{1,2}$. Atualmente aceita-se que a deficiência auditiva pós-meningite bacteriana esteja associada à disseminação da infecção ou do processo inflamatório para o canal auditivo e aqueduto coclear. $\mathrm{O}$ aqueduto coclear apresenta conexão direta com o espaço subaracnóídeo da

Estudo realizado no Hospital Universitário (HU) da Universidade de São Paulo (USP) e no Curso de Fonoaudiologia da Faculdade de Medicina da USP (FMUSP): *Fonoaudióloga dos Setores de Audiologia Clínica e Educacional do Centro de Docência e Pesquisa em Fonoaudiologia da FMUSP, Mestre em Distúrbios da Comunicação pela PUC-SP; **Fonoaudióloga, Bolsista de Aperfeiçoamento do CNPq; ***Livre Docente Doutora do Curso de Fonoaudiologia da FMUSP; ****Neurologista Infantil do Instituto da Criança do Hospital das Clínicas da FMUSP, Doutor em Neurologia; *****Professora Doutora do Curso de Fonoaudiologia da FMUSP; ******Neurofisiologista do Instituto da Criança do Hospital das Clínicas da FMUSP. Pesquisa subvencionada pelo CNPq. Aceite: 27-julho-1999.

Dra. Ida Lichtig - Rua Alberto Faria 102 - 05459-000 São Paulo SP - Brasil. 
fossa média, ou ainda através do saco endolinfático que, embora não se comunique diretamente com o espaço subaracnóídeo, pode ser invadido pela infecção. Uma labirintite serosa ou purulenta pode causar destruição completa ou parcial dos receptores sensoriais do VIII nervo. As formas serosas podem causar deficiência auditiva temporária, mas a infecção local pode determinar a substituição do labirinto membranoso por tecido fibroso e neoformação óssea, determinando deficiência permanente ${ }^{3-5}$. Outros mecanismos possíveis incluem lesão direta da fibra nervosa, dano isquêmico secundário (êmbolo séptico, vasculite com trombose) ${ }^{6,7} \mathrm{e}$ acometimento das vias auditivas centrais ${ }^{5}$.

Os objetivos deste estudo foram: 1) avaliar a presença de alterações auditivas em crianças com diagnóstico de meningite bacteriana, 2) verificar a evolução do quadro audiológico através de reavaliações periódicas, e 3) detectar nas crianças com acuidade auditiva normal alterações do processamento auditivo central.

\section{MÉTODO}

Oitenta e nove crianças internadas no HU/USP com diagnóstico de meningite bacteriana foram submetidas a avaliação audiológica e reavaliadas periodicamente, após alta hospitalar, durante o período de 1988 a 1995. Destas, $55 \%$ eram do sexo masculino e $45 \%$ do sexo feminino. A idade das crianças no período de internação variou de 7 dias a 12 anos, sendo que a maioria destas (57\%) tinha menos de 2 anos de idade (Tabela 1). Os agentes etiológicos responsáveis pelas meningites bacterianas foram $53 \%$ por Neisseria meningitidis, $29 \%$ não especificada, $10 \%$ por Haemophilus influenzae e $8 \%$ por Streptococcus pneumoniae. O tempo entre os primeiros sintomas e a internação variou de 6 horas a 15 dias; o tempo de internação no hospital variou de 6 a 80 dias; e o tempo entre os primeiros sintomas e o primeiro atendimento no ambulatório fonoaudiológico variou de 20 dias a 22 meses.

As avaliações e os seguimentos audiológicos foram realizados no Ambulatório de Neuropediatria do HU-USP e no setor de Audiologia Clínica do Centro de Docência e Pesquisa em Fonoaudiologia da FMUSP. Dezenove crianças compareceram apenas uma vez ao ambulatório; as demais crianças foram acompanhadas e reavaliadas em média por um período de 16 meses, com frequência média de 4 reavaliações.

O processo de avaliação foi iniciado com anamnese, na qual o informante (mãe ou responsável) forneceu dados de identificação da criança, exposição do problema, história familiar, antecedentes pessoais, questões específicas relativas à meningite, história do desenvolvimento motor-audição-fala-linguagem, história socialemocional-educacional e informações sobre a saúde geral da criança.

A inspeção do meato acústico externo era realizada de rotina nas crianças, em todas as faixas etárias, antecedendo os testes auditivos.

A fim de acompanhar o desenvolvimento do comportamento auditivo de crianças (com menos de 24 meses ) até o segundo ano de vida, foi utilizado o Hear Kit, conjunto de 5 instrumentos sonoros, elaborado por Downs em 1984. Estes instrumentos sonoros foram submetidos a análise de suas características acústicas (faixa de frequência e intensidade) podendo ser utilizado para detectar deficiência auditiva de graus moderado a profundo além de avaliar o desenvolvimento da função de localização da fonte sonora.

Com as crianças de 5 meses até 2 anos de idade e com aquelas que não colaboravam foi feita a triagem auditiva com o Audiômetro Pediátrico PA2 (Interacoustics) que produz estímulos com frequência modulada $(500,1000,2000$ e $4000 \mathrm{~Hz})$ em intensidades que variam de 20 a $80 \mathrm{~dB}$.

Nas crianças com mais de um ano de idade foi realizada a avaliação imitanciométrica, com os aparelhos Madsen ZS76-IB e Grason Stadler GSI-33, que incluiu o traçado timpanométrico e a pesquisa de reflexo estapediano.

Para avaliação audiométrica realizada com crianças com mais de 2 anos de idade, nas frequências de 500, 1000, 2000, 4000 e $8000 \mathrm{~Hz}$, foram utilizados equipamentos Madsen ZIS 76 e Grason Stadler GSI-16.

As crianças foram submetidas também a avaliação do potencial evocado auditivo de tronco encefálico, realizado no Serviço de Neurofisiologia do HU-USP, através do aparelho da marca Nihon Koden, modelo Neuropac Mem - 4104. Além da avaliação das latências entre as ondas, foi efetuado o estudo do limiar auditivo, estimado através do estímulo mais fraco, capaz de provocar a onda $\mathrm{V}$.

Os testes de processamento auditivo foram realizados com as crianças cuja acuidade auditiva foi considerada dentro da normalidade (audiometria tonal com limiares até 25dBNA). Estes testes foram:

- provas de triagem para desordem do processamento auditivo conforme protocolo do serviço de Audiologia Clínica do Centro de Docência e Pesquisa em Fonoaudiologia da FMUSP, adaptado de Pereira ${ }^{9}$ compreendendo: 
Tabela 1. Distribuição por faixa etária das crianças com meningite bacteriana.

\begin{tabular}{ll}
\hline Faixa etária & $\%$ \\
\hline até 1 ano e 11 meses & 57 \\
2 a 3 anos e 11 meses & 17 \\
4 a 6 anos e 11 meses & 14 \\
7 a 12 anos & 12 \\
Total & 100 \\
\hline
\end{tabular}

Tabela 2. Distribuição do grau da deficiência auditiva das 22 orelhas de crianças com diagnóstico de deficiência auditiva neurossensorial.

\begin{tabular}{lcc}
\hline Grau da perda & No. de Orelhas & $\%$ \\
\hline Leve & 5 & $22,7 \%$ \\
Moderadamente severa & 2 & $9,1 \%$ \\
Severa & 2 & $9,1 \%$ \\
Profunda & 13 & $59,1 \%$ \\
Total & 22 & $100 \%$ \\
\hline
\end{tabular}

a) pesquisa de reflexo cócleo palpebral (agogô em nível de intensidade estimado entre 85 e 95 dBA), b) memória sequencial para som verbal e c) respostas auditivas de localização da fonte sonora em 5 direções (guizo).

- prova de reconhecimento de sentenças com mensagem competitiva, nas modalidades ipsilateral e contralateral (PSI - Paediatric Sentences Identification - adaptado por Almeida e col, $)^{10}$.

\section{RESULTADOS}

Dentre as 89 crianças submetidas a avaliação audiológica (audiometria tonal, imitanciometria e potencial evocado), $76(85,4 \%)$ apresentaram acuidade auditiva normal e $13(14,6 \%)$ deficiência auditiva neurossensorial, sendo 9 (10,1\%) bilateral e 4 (4,5\%) unilateral (Fig 1).

Analisando segundo o número de orelhas, a Tabela 2 mostra o grau da deficiência auditiva das 22 orelhas das crianças com diagnóstico de deficiência auditiva neurossensorial, que equivalem às 9 crianças com deficiência auditiva bilateral e 4 com deficiência auditiva unilateral.

Todas as crianças com diagnóstico de deficiência auditiva bilateral $(\mathrm{N}=9)$ foram encaminhadas para seleção de aparelho de amplificação sonora individual e para terapia fonoaudiológica. Três das quatro crianças com diagnóstico de deficiência auditiva unilateral foram encaminhadas para terapia fonoaudiológica. Destas últimas, duas realizaram exames para seleção de aparelho auditivo, porém os resultados não foram favoráveis para a indicação.

O seguimento audiológico periódico das crianças com diagnóstico de meningite bacteriana foi realizado para verificar a ocorrência ou não da alteração da acuidade auditiva. Das 89 crianças com avaliação audiológica completa, 64 delas compareceram à primeira avaliação audiológica antes dos 6 meses após a alta hospitalar. Nenhuma criança apresentou piora no grau da deficiência auditiva.

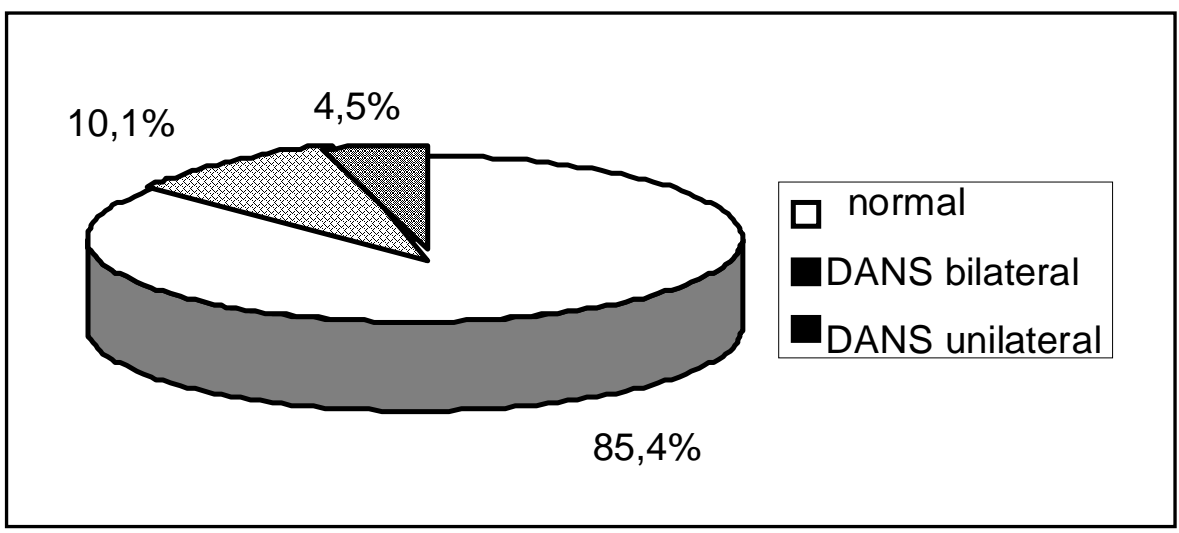

Fig 1. Distribuição da acuidade auditiva das 89 crianças acometidas de meningite bacteriana. 
Uma $(1,54 \%)$ dentre as 64 crianças apresentou melhora na acuidade auditiva. Neste caso, o diagnóstico inicial, feito um mês depois da alta hospitalar, foi de deficiência auditiva neurossensorial bilateral de grau severo a profundo, com níveis de resposta melhores na orelha direita; 17 meses após alta hospitalar o diagnóstico mudou sendo que havia deficiência auditiva neurossensorial profunda no ouvido esquerdo e leve no ouvido direito.

Os testes de processamento auditivo central realizados nas crianças com acuidade auditiva normal não foram utilizados em todas as crianças, seja por abandono, idade insuficiente para avaliação, distúrbio articulatório ou comprometimento de orelha média. Observou-se que:

1) Pesquisa do reflexo cócleo-palpebral (RCP), realizado em 44 (57,9\%) das crianças ouvintes: resposta positiva em $100 \%$ dos casos testados.

2) Avaliação da memória sequencial para som verbal, realizada em $10(13,2 \%)$ das crianças ouvintes: respostas normais em $100 \%$ dos casos.

3) Localização da fonte sonora, utilizando o guizo, realizada em 26 crianças: 20 (77\%) apresentaram respostas dentro do esperado e 6 (23\%) abaixo do esperado 9 . Com relação aos resultados da localização da fonte sonora utilizando o Hear Kit (crianças abaixo de 2 anos), dentre as 46 crianças avaliadas até completarem 24 meses, todas apresentaram resposta abaixo do plano lateral da orelha dentro do esperado; e 50\% apresentaram respostas de localização acima do plano lateral da orelha abaixo do esperado ${ }^{8}$.

4) Prova de reconhecimento de sentenças com mensagem competitiva ipsilateral realizado em 11 crianças: $9(81,8 \%)$ apresentaram resultados dentro da normalidade em ambas orelhas (AO) e $2(18,2 \%)$ apresentaram resultados abaixo do esperado em AO. Destas últimas, uma não realizou a prova de reconhecimento na modalidade contralateral e a outra apresentou resultado do teste contralateral dentro dos parâmetros de normalidade.

5) Prova de reconhecimento de sentenças com mensagem competitiva contralateral, realizado em 9 sujeitos: resultados dentro da normalidade em 100\% dos casos.

\section{DISCUSSÃO}

As complicações mais frequentes na meningite bacteriana são: coleção subdural, abscesso cerebral, hidrocefalia, ventriculite e envolvimento de nervos cranianos ${ }^{2}$. Dentre estes últimos, a meningite pode afetar o nervo oculomotor e o nervo vestibulococlear, acarretando respectivamente a deficiência visual (em 2 a 4\%) e a deficiência auditiva (em 2,4 a 29\%) $)^{11-13}$.

Os resultados deste estudo, evidenciaram que 14,6\% das crianças acometidas com meningite bacteriana apresentaram deficiência auditiva, corroborando com os dados das referências ${ }^{4,6,12}$.

Ainda não se tem o conhecimento do exato momento em que é estabelecida a deficiência auditiva em crianças com diagnóstico de meningite bacteriana. Kaplan e col. ${ }^{1}$ desenvolveram estudo com o objetivo de avaliar a presença de alterações auditivas, a fim de determinar se a deficiência auditiva ocorre no início do curso da doença. Para tanto, verificaram o potencial evocado auditivo do tronco cerebral em 37 crianças nas primeiras 48 horas de admissão. Os resultados revelaram que somente 4 destas crianças tinham deficiência auditiva detectada na admissão. No seguimento, duas apresentaram deficiência auditiva permanente e as outras duas recuperaram a audição completa ou parcialmente; não houve caso de criança que desenvolveu deficiência auditiva no seguimento ambulatorial. Os autores concluíram que a deficiência auditiva ocorre no início do curso da doença em algumas crianças.

A melhora da acuidade auditiva em um dos pacientes do presente estudo ocorreu provavelmente pela possibilidade de estar a alteração relacionada a componente inflamatório, pelo menos parcialmente, de tipo seroso ${ }^{4,5,14}$. Conforme Rosenhal e col. ${ }^{15}$ é possível ocorrer o aparecimento ou a piora da deficiência auditiva nos 6 meses seguintes ao acometimento, apesar de extremamente raro, o que não foi encontrado em nosso estudo, em que as crianças foram acompanhadas durante 16 meses, em média. Keith descreve que a meningite bacteriana pode apresentar, dentre outras sequelas, distúrbios nas habilidades de processamento auditivo ${ }^{16}$. 
Nas crianças submetidas à triagem das habilidades de processamento auditivo, os resultados obtidos mostraram que, apesar da acuidade auditiva normal, elas apresentaram prejuízo na habilidade de localizar a fonte sonora e de lidar com informações auditivas pouco redundantes, devido à presença de mensagem competitiva ipsilateral. Tanto a prova de localização da fonte sonora como a de reconhecimento de sentenças com mensagem competitiva ipsilateral são sensíveis para detectar alteração auditiva central, principalmente no tronco encefálico ${ }^{17}$, mais exatamente no complexo olivar superior e no colículo inferior. Estes núcleos oferecem base anatômica para função binaural, pois as diferenças de tempo interaural e a intensidade são determinantes para localização da fonte sonora; a convergência da informação neural de cada ouvido nestes núcleos atribui uma regra crítica nas provas de escuta, que requerem integração dos sinais apresentados binauralmente ${ }^{18}$.

Para todas as crianças que apresentaram alterações nas habilidades de processamento auditivo, as famílias foram orientadas para realizar estimulação auditiva. Porém, para aquelas cuja evolução não ocorria conforme o esperado, foi necessário fazer o encaminhamento para terapia fonoaudiológica. Durante o seguimento audiológico ambulatorial, as mães ou responsáveis relataram alteração no comportamento geral das crianças após alta hospitalar. Relataram que as crianças ficaram mais agitadas, "desajeitadas", distraídas, não responsivas às solicitações e às vezes necessitando repetir as mensagens. Estas características comportamentais das crianças são também descritas na literatura como compatíveis aos indivíduos portadores de desordens de processamento auditivo ${ }^{16}$.

Para concluir, é imprescindível enfatizar a necessidade de medidas preventivas contra as meningites, as quais continuam evoluindo com grande número de sequelas, apesar de todos os avanços terapêuticos. As alterações auditivas acarretam prejuízos no desenvolvimento linguistico, emocional, social e educacional nas crianças que apresentaram meningite bacteriana.

\section{REFERÊNCIAS}

1. Kaplan SL, Catlin FI, Weaver T, Feigin RD. Onset of hearing loss in children with bacterial meningitis. Pediatrics 1984;73:575-578.

2. Osmo A, Casella EB. Meningites bacterianas. Revisões Pediátricas 1991; vol 3.

3. Altmann F. Post-meningitic labyrinth ossification with stapes fixation. Arch Otolaryngol. 1965;82:470-477.

4. Liebman EP, Ronis ML, Lovrinic JH, Katinsky SE. Hearing improvement following meningitis deafness. Arch Otolaryngol 1969;90:470-475.

5. Roeser RJ, Campbell JC, Daly DD. Recovery of auditory function following meningitic deafness. J. Speech Hear Dis 1975;40:405-411.

6. Vienny II, Despland PA, Lutshg J, Deonnat T, Dutoit-Marco ML, Gander C. Early diagnosis and evolution of deafness in childhood bacterial meningitis: a study using brainstem auditory evoked potentials. Pediatrics 1984;73:579-586.

7. Jiang ZD, Liu XY, Wu YY, Zheng MS, Liu HC. Long-term impairments of brain and auditory functions of children recovered from purulent meningitis. Dev Med Child Neurol 1990;32:473-480.

8. Downs MP. Hearing screening guide. University Park Station, Colorado: Bam Worldmarkets, 1984.

9. Pereira LD. Processamento auditivo. Temas sobre Desenvolvimento 1993;2:7-14.

10. Almeida CIR, Campos MI, Almeida RR. Logoaudiometria pediátrica: PSI (Pediatric speech intelligibility test). Rev Bras Otorrinolaringol 1988;54:73-76.

11. Sell SHW, Merril RE, Doyne EO, Zimsky EP. Long-term sequelae of Hemophilus influenza meningitis. Pediatrics 1972;49:206-211.

12. Dodge PR, Davis H, Feigin RD, et al.. Prospective evaluation of hearing impairment as a sequela of acute bacterial meningitis. N Engl J Med 1984;311:869-874.

13. Casella EB. Sequelas de meningite meningogócica em crianças: análise crítica do uso da dexametasona. Tese, Faculdade de Medicina da Universidade de São Paulo, São Paulo,1995.

14. Lichtig I, Couto MIV, Monterio SRG, Casella EB, Okay Y, Navarro J. Evolução do comportamento auditivo após meningite bacteriana: relato de caso. Arq Neuropsiquiatr 1997;55:334-338.

15. Rosenhal U, Nylen O, Lindenberg J, Kankkunen A. Auditory function after Haemophilus influenza meningitis. Acta Otolaryngol 1978;85:243-247.

16. Keith RW. Tests of central auditory function. In Roeser RJ, Downs MP. Auditory disorders in school children. New York: Thieme-Stratton,. 1981:159-176.

17. Ziliotto KN, Kalil DM, Almeida CIR. PSI em Português. In Pereira LD, Schochat E. Processamento auditivo central: manual de avaliação. São Paulo: Editora Lovise, 1997:113-128.

18. Musiek FE, Lamb L. Neuroanatomy and neurophysiology of central auditory processing. In Katz J, Stecker NA, Henderson D. Central auditory processing: a transdisciplinary view. St. Louis: Mosby Year Book, 1992:11-38. 